\title{
Sandwich Electrochemical Immunosensor for Early Detection of Tuberculosis Based on Graphene/Polyaniline-Modified Screen-Printed Gold Electrode
}

\author{
Umi Zulaikha Mohd Azmi ${ }^{1}$, Nor Azah Yusof ${ }^{1,2, *}$, Norzila Kusnin ${ }^{1}$, Jaafar Abdullah ${ }^{1,2}$, \\ Siti Suraiya ${ }^{3}$, Poh Shing Ong ${ }^{4}$, Nurul Hanun Ahmad Raston ${ }^{5}$, Siti Fatimah Abd Rahman ${ }^{1, *}$ \\ and Mohamad Faris Mohamad Fathil ${ }^{6}$ \\ 1 Institute of Advanced Technology, Universiti Putra Malaysia, Serdang 43400, Selangor, Malaysia; \\ umizulaikha.ika@gmail.com (U.Z.M.A.); norzilakusnin87@gmail.com (N.K.); jafar@upm.edu.my (J.A.) \\ 2 Department of Chemistry, Faculty of Science, Universiti Putra Malaysia, Serdang 43400, Selangor, Malaysia \\ 3 School of Medical Sciences, Universiti Sains Malaysia, Kubang Kerian, Kelantan 16150, Malaysia; \\ ssuraiya@usm.my \\ 4 NanoMalaysia Berhad, a CLG under the Ministry of Energy, Science, Technology, Environment and Climate \\ Change (MESTECC), Kuala Lumpur 50450, Malaysia; pohshing.ong@nanomalaysia.com.my \\ 5 School of Biosciences and Biotechnology, Faculty of Science and Technology, Universiti Kebangsaan \\ Malaysia, UKM Bangi 43600, Selangor, Malaysia; nurulhanun@ukm.edu.my \\ 6 Institute of Nano Electronic Engineering, Universiti Malaysia Perlis, Kangar 01000, Perlis, Malaysia; \\ mohamadfaris@unimap.edu.my \\ * Correspondence: azahy@upm.edu.my (N.A.Y.); siti_fatimahar@upm.edu.my (S.F.A.R.); \\ Tel.: +60-389-466-782 (N.A.Y.); +60-125-752-444 (S.F.A.R.)
}

Received: 14 August 2018; Accepted: 12 October 2018; Published: 14 November 2018

\begin{abstract}
A rapid and sensitive sandwich electrochemical immunosensor was developed based on the fabrication of the graphene/polyaniline (GP/PANI) nanocomposite onto screen-printed gold electrode (SPGE) for detection of tuberculosis biomarker 10-kDa culture filtrate protein (CFP10). The prepared GP/PANI nanocomposite was characterized using Fourier transform infrared spectroscopy (FTIR) and field emission scanning electron microscopy (FESEM). The chemical bonding and morphology of GP/PANI-modified SPGE were studied by Raman spectroscopy and FESEM coupled with energy dispersive X-ray spectroscopy, respectively. From both studies, it clearly showed that GP/PANI was successfully coated onto SPGE through drop cast technique. Cyclic voltammetry was used to study the electrochemical properties of the modified electrode. The effective surface area for GP/PANI-modified SPGE was enhanced about five times compared with bare SPGE. Differential pulse voltammetry was used to detect the CFP10 antigen. The GP/PANI-modified SPGE that was fortified with sandwich type immunosensor exhibited a wide linear range (20-100 $\mathrm{ng} / \mathrm{mL}$ ) with a low detection limit of $15 \mathrm{ng} / \mathrm{mL}$. This proposed electrochemical immunosensor is sensitive, low sample volume, rapid and disposable, which is suitable for tuberculosis detection in real samples.
\end{abstract}

Keywords: tuberculosis; electrochemical sensor; screen-printed gold electrode (SPGE); graphene; polyaniline

\section{Introduction}

Globally, one of the most critical infectious diseases is tuberculosis (TB), which can be fatal [1]. Mycobacterium tuberculosis (M. tuberculosis) is the causative agent of TB which can be transmitted via minute aerosol droplets such as coughing, sneezing, or even talking by the infected TB person [2]. This'airborne contagious disease poses a particular infection-control challenge since the healthy person 
can be infected by inhalation of an infectious droplet containing $M$. tuberculosis that suspended in the air. As a result, each year millions of people are infected, making TB the second leading cause of death after the human immunodeficiency virus (HIV) infection [3].

Instead of lung infection, one of the hallmarks of the M. tuberculosis is the ability of the bacteria to spread to other parts of the body through the blood circulation in the infected person. In this regard, the consequences of delayed diagnosis of TB are serious for both the prognosis of the patient and onward transmission to drive the epidemic. A diagnostic test that can be conducted at a single-visit, with theoretical 100\% accuracy could save 625,000 lives a year if widely implemented [4]. However, even a test with a sensitivity of only $85 \%$ and specificity of $97 \%$ could save 392,000 lives, equal to $22 \%$ of the current annual global deaths attributable to TB [4]. In developing countries, sputum smear microscopy currently remains a main tool of diagnosing TB [5]. However, this method depends on both the quality and bacterial load of the sputum specimen as well as the skills of laboratory technicians. In addition, the smear microscopy is insensitive with the reported sensitivity only about 60\% [6]. The culture-based systems have been developed and offer relative improvements in sensitivity over conventional techniques by combining $M$. tuberculosis culture and monitoring in one tube, which known as mycobacteria growth indicator tube (MGIT) [7]. However, this technique is more expensive than microscopy, requires up to ten days culturing time and a high standard of technical competence. Thus, there is an unmet need for reliable diagnostic methods to identify TB disease rapidly and accurately in an economic way, as replacement for the time consuming, complex and costly technique.

These requirements can be accomplished by using biosensors platform, with particular reference to the electrochemical immunosensors. Their low cost, small size and highly sensitive nature are making them have a great impact on the development of rapid assays for TB diagnosis in clinical use. In addition, the use of screen-printed electrodes (SPEs)-based biosensors represents the most favorable strategy for on-site and one-shot sensors (disposable) analysis, since the screen-printed technology has the ability to be easily mass produced [8-10]. Moreover, the modification of electrode with nanomaterials will certainly provide an effective way to improve the analytical performance. Graphene (GP)-based nanomaterials have attracted enormous interest in electrochemical sensors due to their extraordinary properties such as large surface area, high electrical conductivity and biocompatibility [11-13]. This strategy may be effective in the combination of use with polyaniline (PANI), one of the promising and unique conducting polymers for sensor development [14]. PANI provides fast electron dynamics and excellent electrochemical activity [15]. The conjunction of PANI with GP (PANI/GP) may prevent the introduction of defects into GP substrate and preserves GP's electrical characteristics.

Genosensor constructed for the detection of nucleic acid hybridization could represent a valid method for TB diagnosis [16-18]. Although same-day diagnosis is possible with the molecular assay, usage is currently limited by the relatively high cost. To overcome this challenge, an alternative strategy to develop an economical TB diagnosis test for resource-constrained area is based on the detection of antigens in body fluids. Various tests have been developed to detect Mycobacterial antigens in sputum [19,20], cerebrospinal fluid [21] and urine [22] in TB patients using ELISA for antigen recognition. Indeed, Reither et al. reported that although the ELISA assays were effective in TB detection, however, the assay is semi-quantitative and the sensitivity could be significantly improved [23].

Here, we demonstrate a novel practical approach to develop a disposable immunoassay-based screen-printed gold electrode (SPGE) for TB detection, employing ESAT-6-like protein esxB (CFP10) as a protein biomarker. Noteworthy, CFP10 which is a $10 \mathrm{kDa}$ secreted antigen from $M$. tuberculosis has been selected as a sensitive platform for the detection of early bovine TB infection [24]. An interesting approach based on a two-step strategy, which included GP/PANI-modified electrode and a sandwich immunoassay format was used in order to amplify the detection signal as well as increase the selectivity of the sensor towards the TB-specific biomarkers. The sandwich-type immunoassay format was 
developed by immobilizing the capture anti-CFP10 antibodies (CapAb) onto GP/PANI-modified SPGE to capture CFP10 in the sample and iron oxide-gold magnetic nanoparticles $\left(\mathrm{Fe}_{3} \mathrm{O}_{4}\right.$ - $\left.\mathrm{Au} \mathrm{MNPs}\right)$ conjugated with primary anti-CFP10 antibodies $(\mathrm{Ab})$ served as a signal probe. We also demonstrated the effectiveness of developed immunoassay for the sensitive and quantitative detection of CFP10 in sputum, collected from human samples of TB infected persons. These studies suggested that the blood test-free method through sputum detection of biomarkers such as CFP10 might be of value in the early detection of TB disease, especially in HIV-positive cases and thus could provide wide potential applications in clinical analysis.

\section{Materials and Methods}

\subsection{Materials and Reagents}

M. tuberculosis CFP10 antigen and polyclonal anti-CFP10 antibody were obtained from Cusabio (Houston, TX, USA). Tetramethylammonium hydroxide (TMAOH), tetrachloroauric acid hydrate $\left(\mathrm{HAuCl}_{4}\right)$, bovine serum albumin (BSA), potassium hexacyanoferrate (III), tri-sodium citrate, 2-mercaptoethanol (ME), 12-mercaptododecanoic acid (MDDA), graphene powder, aniline, poly (methylvinylether-alt-maleic acid) (PMVEA), ammonium persulfate (APS) and (3-aminopropyl) triethoxysilane (APTES) were purchased from Sigma-Aldrich (St. Louis, MO, USA). Iron (III) chloride $\left(\mathrm{FeCl}_{3}\right)$ and absolute ethanol were purchased from HmbG Chemicals (Hamburg, Germany). N-hydroxysuccinimide (NHS) and 1-ethyl-3-(3-dimethylaminopropyl)-carbodiimide (EDC) were obtained from Alfa Aeser (Lancaster, KA, UK) and Fluka (Ronkonkoma, NY, USA), respectively. Hydroxylamine hydrochloride $\left(\mathrm{NH}_{2} \mathrm{OH} \cdot \mathrm{HCl}\right)$, sodium hydroxide $(\mathrm{NaOH})$ and iron (II) sulphate $\left(\mathrm{FeSO}_{4}\right)$ were purchased from R\&M Chemicals (Essex, UK). All cyclic voltammetry (CV) measurements were performed in $1.00 \mathrm{mM} \mathrm{K}_{3} \mathrm{Fe}(\mathrm{CN})_{6}$ with $50 \mathrm{mM} \mathrm{KCl}$, while the differential pulse voltammetry (DPV) measurements were carried out in $0.01 \mathrm{M}$ phosphate buffered saline (PBS) with $\mathrm{pH} 7.4$. The $0.5 \mathrm{M}$ of sulphuric acid (Sigma, St. Louis, MO, USA) was used to activate the SPGE before modification. Real samples (sputum) were obtained from Hospital Universiti Sains Malaysia (Kubang Kerian, Kelantan, Malaysia). All chemicals are of the qualitative analytical grade. Deionized (DI) water was used to prepare the aqueous solutions.

\subsection{Apparatus}

Electrochemical measurements were performed using potentiostat Metrohm ${ }^{\circledR} \mu$ Autolab type III (Eco Chemie, Utrecht, The Netherlands) integrated with screen printed junction cable controlled by NOVA 1.11 software. The SPGE was purchased from DropSens (Oviedo, Spain). The diameter of the disk-shaped working electrode was $4 \mathrm{~mm}$. The working electrode and auxiliary electrode were made of gold, whereas the reference electrode was made of silver. The electrodes were all printed on a ceramic support $(\mathrm{L} 33 \times \mathrm{W} 10 \times \mathrm{H} 0.5 \mathrm{~mm}$ ). All electrochemical measurements were performed at room temperature. Field emission scanning electron microscopy (FESEM) analysis was carried out using an FEI Nova Nanosem 230 microscope equipped with an energy dispersive X-ray (EDX) system. Raman spectroscopy studies were performed with a WITec Alpha 300R microscope while Fourier transform infrared spectroscopy (FTIR) coupled with attenuated total reflectance analysis were executed using Shimadzu.

\subsection{Synthesis of Iron Oxide Magnetic Nanoparticles Coated with Gold $\left(\mathrm{Fe}_{3} \mathrm{O}_{4} / \mathrm{Au} \mathrm{MNPs}\right)$}

Magnetic nanoparticles composed of $\mathrm{Fe}_{3} \mathrm{O}_{4}$ and gold nanohybrid material $\left(\mathrm{Fe}_{3} \mathrm{O}_{4} / \mathrm{Au} \mathrm{MNPs}\right)$, in particular, were synthesized via co-precipitation method according to previous reported methods with slight modification [25,26]. Briefly, $25 \mathrm{~mL}$ aqueous solution containing of $0.8 \mathrm{M} \mathrm{FeCl}_{3}, 0.4 \mathrm{M} \mathrm{FeSO}_{4}$, $40 \mathrm{mM} \mathrm{HCl}$ was added drop wise into $1.5 \mathrm{M} \mathrm{NaOH}(250 \mathrm{~mL})$ solution under vigorous stirring using a non-magnetic stirrer. Black $\mathrm{Fe}_{3} \mathrm{O}_{4}$ MNPs formed immediately, which were separated by NdFeB magnet and washed three times with DI water. The $\mathrm{Fe}_{3} \mathrm{O}_{4}$ MNPs were centrifuged for $15 \mathrm{~min}$ at 
$9000 \mathrm{rpm}$. Finally, the $\mathrm{Fe}_{3} \mathrm{O}_{4} \mathrm{MNPs}$ were dispersed in DI water and stored at $4{ }^{\circ} \mathrm{C}$ for further use. To coat the $\mathrm{Fe}_{3} \mathrm{O}_{4}$ MNPs with gold nanoparticles, $5 \mathrm{~mL}$ aliquot of the $\mathrm{Fe}_{3} \mathrm{O}_{4} \mathrm{MNPs}$ and $1.5 \mathrm{~mL}$ of $0.2 \mathrm{M}$ $\mathrm{NH}_{2} \mathrm{OH} \cdot \mathrm{HCl}$ was added into $75 \mathrm{~mL}$ of $0.01 \mathrm{M}$ TMAOH aqueous solution. The solution was heated at $80{ }^{\circ} \mathrm{C}$ under vigorous stirring. Then, $40 \mathrm{mg}$ of $\mathrm{HAuCl}_{4}$ in $40 \mathrm{~mL}$ deionized water was added into the mixture drop by drop, followed by $100 \mathrm{~mL}$ of $15 \mathrm{mM}$ sodium citrate solution was added drop wise. The color of the mixture changed from black to reddish brown gradually. The mixture was heated for another $1 \mathrm{~h}$ and then cooled to room temperature. The formed $\mathrm{Fe}_{3} \mathrm{O}_{4} / \mathrm{Au}$ MNPs were collected by a magnet, followed by centrifuged twice with deionized water and ethanol. Finally, the $\mathrm{Fe}_{3} \mathrm{O}_{4} / \mathrm{Au}$ MNPs was dried at $70{ }^{\circ} \mathrm{C}$ in a vacuum oven for $1 \mathrm{~h}$.

For carboxylation steps, 2-mercaptoethanol and 12-mercaptododecanoic acid (ME-MDDA) was self-assembled on $\mathrm{Fe}_{3} \mathrm{O}_{4} / \mathrm{Au}$ MNPs surface by the well-known gold-thiol (Au-S) chemistry. Then, $10 \mathrm{mg}$ of the $\mathrm{Fe}_{3} \mathrm{O}_{4} / \mathrm{Au}$ MNPs were suspended in $1 \mathrm{mM}$ ethanolic ME-MDDA and incubated for $24 \mathrm{~h}$ at room temperature. The carboxylated nanoparticles were washed several times with water and dispersed in 0.01 M PBS solution with pH 7.4.

\subsection{Immobilization of Primary Anti-CFP10 Antibody on $\mathrm{Fe}_{3} \mathrm{O}_{4} / \mathrm{Au}$ MNPs}

Briefly, $1 \mathrm{~mL}$ functionalized $\mathrm{Fe}_{3} \mathrm{O}_{4} / \mathrm{Au}$ MNPs was mixed with $1 \mathrm{~mL} 25 \mu \mathrm{g} / \mathrm{mL}$ antibody $(\mathrm{Ab})$ solution followed by incubation for $2 \mathrm{~h}$. Subsequently, $\mathrm{Fe}_{3} \mathrm{O}_{4} / \mathrm{Au}-\mathrm{Ab}$ was collected by a magnet and washed three times with $0.01 \mathrm{M}$ PBS solution. Then, $\mathrm{Fe}_{3} \mathrm{O}_{4} / \mathrm{Au}-\mathrm{Ab}$ was re-dispersed in $1 \mathrm{~mL}$ of $1 \%$ $\mathrm{BSA}$ for $2 \mathrm{~h}$ and separated again using a magnet. Finally, $\mathrm{Fe}_{3} \mathrm{O}_{4} / \mathrm{Au}-\mathrm{Ab}$ was washed with PBS again and re-dispersed the particles in PBS solution. The particles were stored at $4{ }^{\circ} \mathrm{C}$ for further use.

\subsection{Preparation of GP/PANI Nanocomposite}

The method to prepare GP/PANI nanocomposite was done according to an in-situ polymerazation procedure previously reported by Mohamad and group [18]. Briefly, $0.2 \mathrm{M}$ aniline and 3 wt $\%$ PMVEA were dissolved in deionized water. Then, the solution was cooled in a refrigerator at $4{ }^{\circ} \mathrm{C}$ for $60 \mathrm{~min}$ and followed by adding a pre-cooled aqueous solution of $0.2 \mathrm{M}$ APS. Next, $50 \%$ weight ratio of GP to aniline was added into the mixture and placed at room temperature at least $6 \mathrm{~h}$ in order to complete the whole reaction for polymerization process. The black-green precipitate was filtered and rinsed with methanol, deionized water and acetone for several times. Finally, the GP/PANI nanocomposite product was dried overnight at $40{ }^{\circ} \mathrm{C}$.

\subsection{Modification of SPGE-Based on Sandwich Immunoassay Format}

The development of sandwich immunosensor for CFP10 detection in this study is depicted in Figure 1. Firstly, the electrode was activated with $0.5 \mathrm{M} \mathrm{H}_{2} \mathrm{SO}_{4}$ solution using CV between $0.0-1.6 \mathrm{~V}$ for 40 cycles, scan rate of $100 \mathrm{mV} / \mathrm{s}$ and dried at room temperature. Then, $1 \mathrm{mg}$ of GP/PANI powder was dispersed in $1 \mathrm{~mL}$ of $2 \%$ APTES solution to prepare GP/PANI solution. Various amount of the GP/PANI solution $(0,4,5,6$ and $7 \mu \mathrm{L})$ was drop casted onto electrode surface and dried overnight at room temperature in order to optimize the GP/PANI thickness on the electrode surface. After washing with ethanol, the electrode was then dried at $70{ }^{\circ} \mathrm{C}$ in the oven for $30 \mathrm{~min}$. The $\mathrm{CapAb}$ was immobilized onto GP/PANI surface through a cross-linker EDC and NHS [27]. The electrode was then washed with PBS and immersed in $4 \mathrm{~mL}$ of $0.25 \%$ BSA solution for $1 \mathrm{~h}$ to avoid non-specific binding. Next, the modified electrode was incubated with $4 \mu \mathrm{L}$ of M. tuberculosis CFP10 antigen solution for $1 \mathrm{~h}$. After washing the electrode, $4 \mu \mathrm{L}$ of the prepared $\mathrm{Fe}_{3} \mathrm{O}_{4} / \mathrm{Au}-\mathrm{Ab}$ buffer solution was drop casted onto the surface and incubated for $40 \mathrm{~min}$. After washing, the electrode was ready for measurement.

All CV measurements were carried out in $1 \mathrm{mM} \mathrm{K}_{3} \mathrm{Fe}(\mathrm{CN})_{6}$ with $50 \mathrm{mM} \mathrm{KCl}$ at potential range from -0.4 to $0.6 \mathrm{~V}$ for 40 cycles at scan rate of $100 \mathrm{mV} / \mathrm{s}$. The DPV measurements were performed in $0.01 \mathrm{M}$ phosphate buffered saline (PBS) with $\mathrm{pH} 7.4$ at potential range from 0.0 to $1.0 \mathrm{~V}$, step potential of $0.009 \mathrm{~V}$ and modulation amplitude of $0.0 \mathrm{~V}$ with the interval time of $0.64 \mathrm{~s}$ at room temperature. 


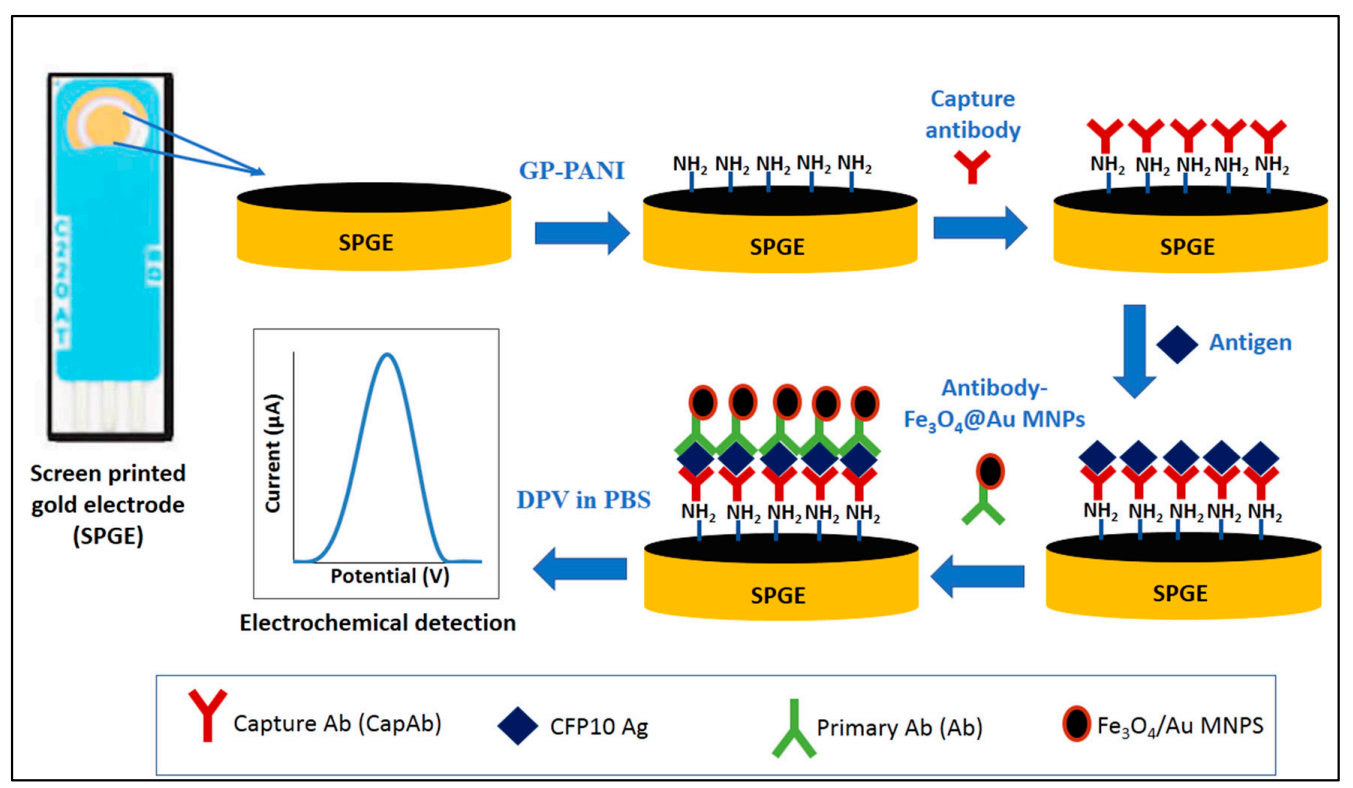

Figure 1. Schematic diagram of the fabrication process of GP/PANI-modified SPGE in sandwich immunoassay format.

\section{Results and Discussion}

\subsection{Characterization of GP/PANI Nanocomposite Material}

Figure 2 shows the scanning electron microscope (SEM) images of GP and GP/PANI nanocomposite. The SEM image of GP (Figure 2a) shows a good lamellar structure and rich wrinkled structures on the surface. Meanwhile, the SEM image of GP/PANI nanocomposite (Figure 2b) shows that the GP sheets are mostly covered with PANI nanofibers and formed cauliflower-like structures. It indicates that the presence of GP promotes the formation of agglomerate PANI nanofibers. Figure $2 \mathrm{c}$ presents IR spectra of GP nanosheet and GP/PANI nanocomposite. The peaks at $1655 \mathrm{~cm}^{-1}$ correspond to the C-C bond in GP. Compared to spectra of GP/PANI nanocomposite, the broad peaks at $1477 \mathrm{~cm}^{-1}$ indicates the $\mathrm{N}-\mathrm{H}$ bond was overlapped with $\mathrm{C}=\mathrm{C}$ aromatic. Besides that, the $\mathrm{C}-\mathrm{N}$ peak appeared at $1274 \mathrm{~cm}^{-1}$ and $1084 \mathrm{~cm}^{-1}$. Therefore, we can conclude that the GP was successfully bound with PANI to form GP/PANI nanocomposite.
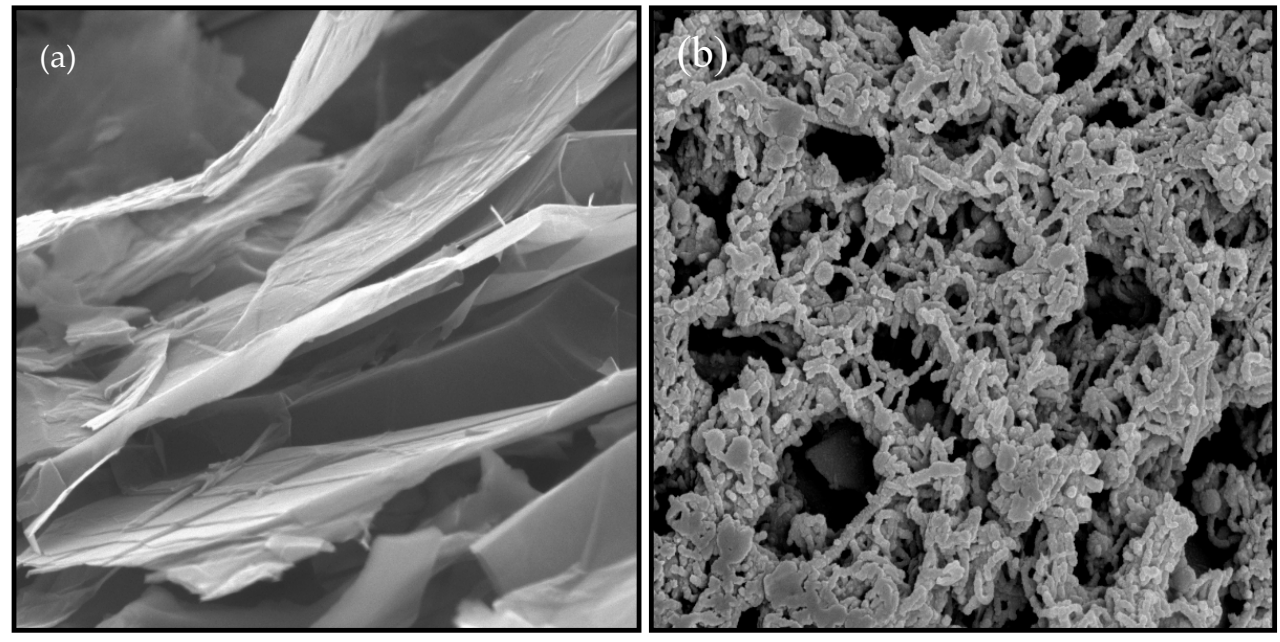

Figure 2. Cont. 


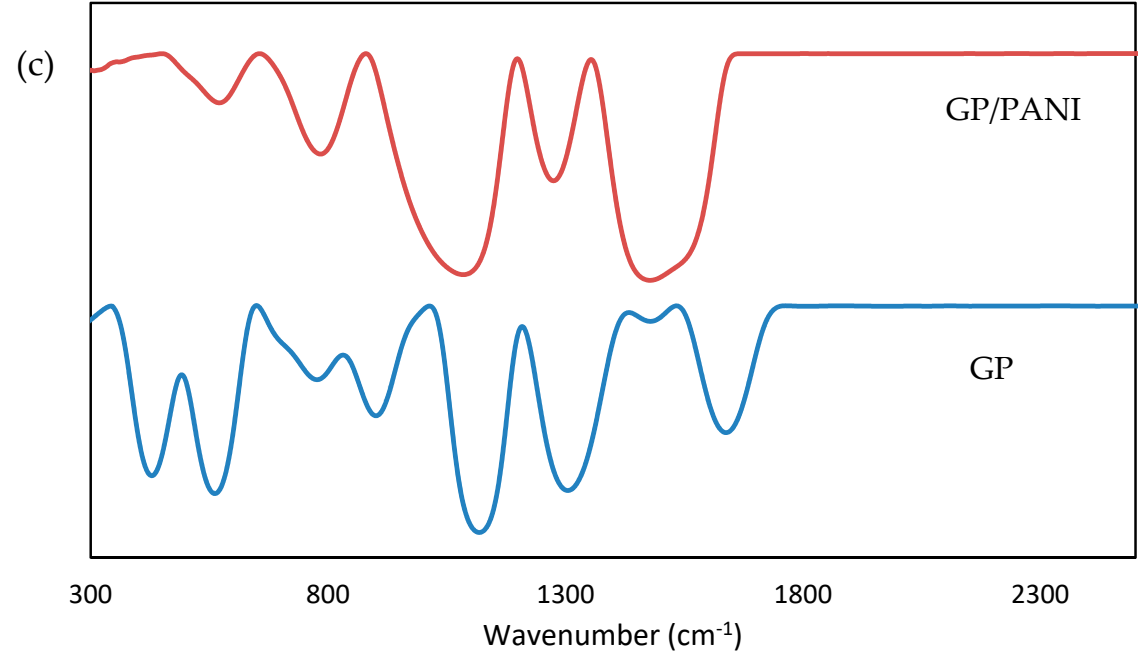

Figure 2. FESEM images of (a) graphene and (b) GP/PANI nanocomposite with magnification of 50k. (c) IR spectra of GP nanosheet and GP/PANI nanocomposite.

\subsection{Characterization of GP/PANI-Modified SPGE}

GP/PANI nanocomposite material was used to modify bare SPGE in order to enhance the sensor performance. The morphology of GP/PANI-modified SPGE surface was studied by FESEM-EDX. It was observed in Figure 3a,b that the surface structure of GP/PANI-modified electrode turned relatively rough and agglomerate compared to bare SPGE due to the formation of nanoparticle clusters on the electrode surface, which resulted in an increase of active surface area [28,29]. The presence of GP/PANI nanocomposite was also confirmed using EDX analysis. The presence of $\mathrm{Si}$ in GP/PANI-modified SPGE as depicted in Figure $3 \mathrm{~b}$ was due to the APTES used as a dispersion agent. Meanwhile, the existence of N, O and a significant increase of $\mathrm{C}$ in GP/PANI-modified SPGE clearly indicated that the GP/PANI was successfully bound to the surface of SPGE. In addition, Raman spectroscopy was used to identify the presence of PANI in GP/PANI-modified electrode. As shown in Figure 3c, the spectrum of the GP-modified SPGE clearly shows three bands at 1350, 1580 and $2700 \mathrm{~cm}^{-1}$ which represent D, G and 2D bands, respectively. The G band represents the in-plane bond-stretching motion of the pairs of carbon $\mathrm{sp}^{2}$ atoms, while the $\mathrm{D}$ band is related to the conversion of a sp $\mathrm{s}^{2}$-hybridized carbon to a sp ${ }^{3}$-hybridized carbon [18]. Compared with graphene, the D band of PANI showed a slight shift to higher frequencies, probably due to the strong long-range $\pi-\pi$ and electrostatic interaction between PANI and GP-modified SPGE [30].

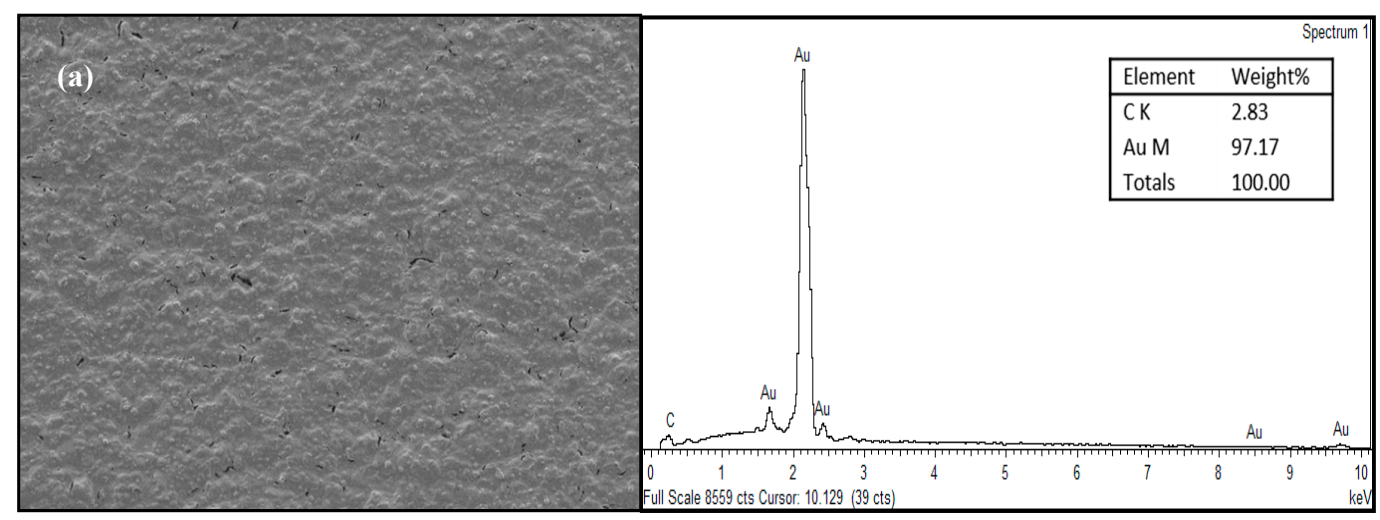

Figure 3. Cont. 

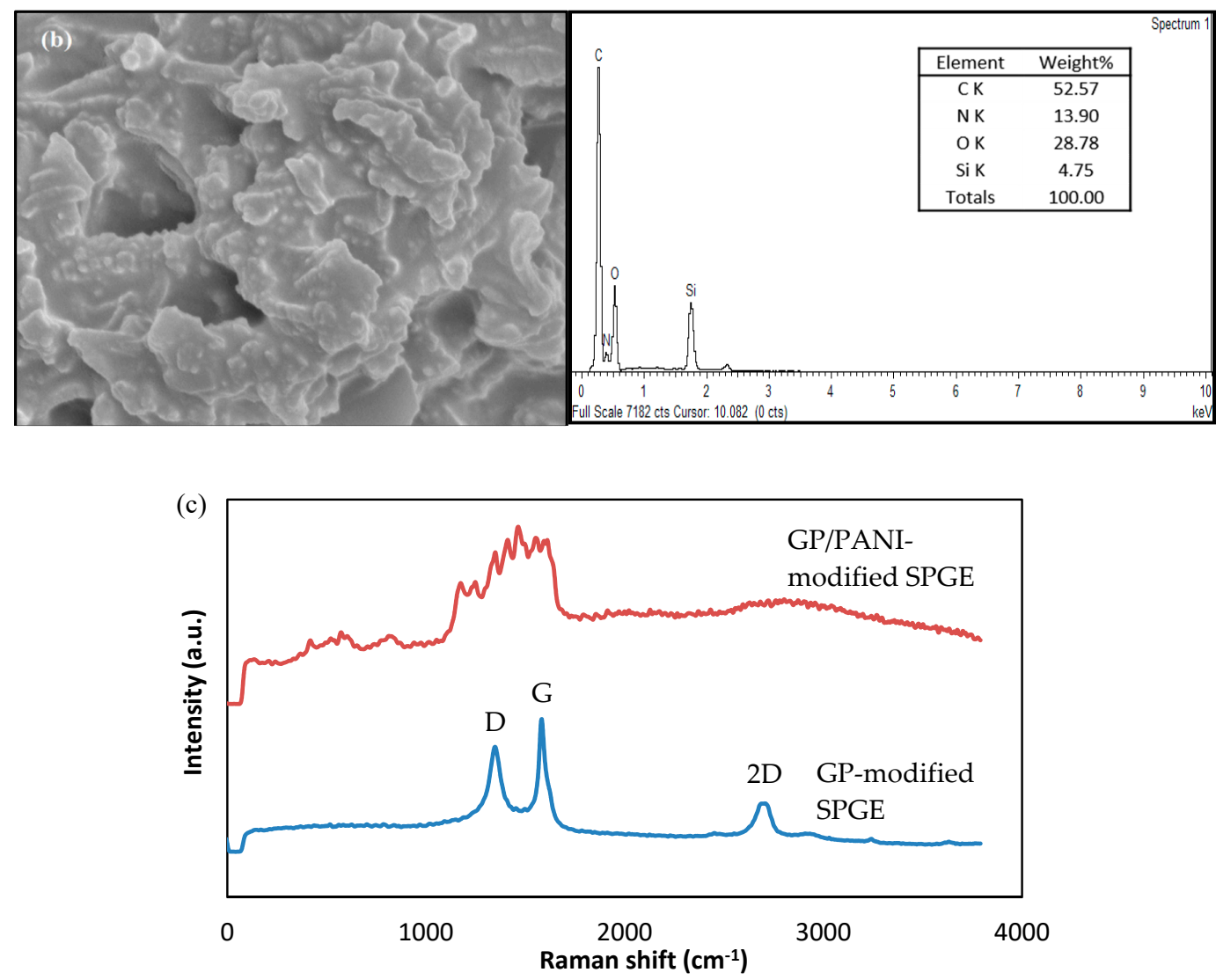

Figure 3. FESEM images coupled with EDX spectra of (a) bare SPGE and (b) GP/PANI-modified SPGE. (c) Raman spectra of GP-modified SPGE and GP/PANI-modified SPGE.

Next, the electrochemical behavior of GP/PANI-modified SPGE in potassium ferricyanide $\left(\mathrm{K}_{3} \mathrm{Fe}(\mathrm{CN})_{6}\right)$ solution was investigated. $\mathrm{K}_{3} \mathrm{Fe}(\mathrm{CN})_{6}$ solution was used to study the electrocatalytic response of GP/PANI nanocomposite coated SPGE surface using the CV technique. It is notable that Ferrocyanide ion has been a good redox indicator for the analysis of the redox properties of modified electrodes due to its reversibility and rapid electrochemical reactions [31]. Moreover, it is believed that the thickness of GP/PANI nanocomposite on surface modification of SPGE played a crucial role for sensor performance. In this regard, we have studied different amounts of GP/PANI solution coated onto SPGE.

As depicted in Figure 4a, the sensor electrode with modification of $4 \mu \mathrm{L}$ GP/PANI solution shows the highest current value approximately $50 \mu \mathrm{A}$. As the volume of GP/PANI solution was increased to 5 and $6 \mu \mathrm{L}$, the value of peak current decreased to 33 and $15 \mu \mathrm{A}$, respectively. However, it is noted that the peak current was slightly increased to $20 \mu \mathrm{A}$ as the volume of GP/PANI solution increased to $7 \mu \mathrm{L}$. This could happen to the optimized value of $4 \mu \mathrm{L}$ GP/PANI solution that gives highest surface electrostatic interactions, as compared to the GP/PANI volume solutions of 5, 6 and $7 \mu \mathrm{L}$. On the other hand, $4 \mu \mathrm{L}$ of GP/PANI solution provides more stable of current observation (in terms of standard deviation) and higher peak current than bare SPGE. Thus, the thickness of GP/PANI particles on a SPGE electrode is crucial as it will affect the electrochemical performance. In this work, $4 \mu \mathrm{L}$ GP/PANI solution was used to modify the SPGE surface.

To monitor the performance of the GP/PANI-modified SPGE for immunosensor development, the effective surface area for the electrode was studied and determined. To study the effective surface area of the electrode, the $\mathrm{CV}$ was performed in $1 \mathrm{mM} \mathrm{K}_{3} \mathrm{Fe}(\mathrm{CN})_{6}$ containing $50 \mathrm{mM} \mathrm{KCl}$ solution 
at different scan rates $(10-100 \mathrm{mV} / \mathrm{s})$. The effective surface area can be estimated according to the Randles-Sevcik equation [7].

$$
\mathrm{I}_{\mathrm{p}}=2.69 \times 10^{5} \mathrm{~A} \times \mathrm{D}^{1 / 2} \mathrm{n}^{2 / 3} \mathrm{Cv}^{1 / 2},
$$

where $I_{p}$ represents the oxidation peak current $(\mu \mathrm{A}), n=1$ which is the number of electrons transferred, $\mathrm{D}$ is the diffusion coefficient of ferricyanide solution $\left(7.6 \times 10^{-6} \mathrm{~cm}^{2} / \mathrm{s}\right)$ [29], A is the electrode surface area (A) $\left(\mathrm{cm}^{2}\right), \mathrm{C}$ is the concentration of ferricyanide $\left(\mathrm{mol} / \mathrm{cm}^{3}\right)$ and $\mathrm{v}$ is the scan rate $(\mathrm{V} / \mathrm{s})$. Based on the graph of $I_{p}$ versus $v^{1 / 2}$ as shown in Figure $4 b$, the effective surface area values of bare SPGE and GP/PANI-modified SPGE were calculated as 0.101 and $0.535 \mathrm{~cm}^{2}$, respectively. The utilization of GP/PANI nanocomposite as electrochemical enhancer has led to five times greater sensor performance with respect to the bare SPGE. In addition, the linear relationship between redox peak current of GP/PANI-modified SPGE versus square root of scan rate $\left(\mathrm{v}^{1 / 2}\right)$ reveals that the electrochemical reaction of the ferricyanide surface is a diffusion-controlled process [29].
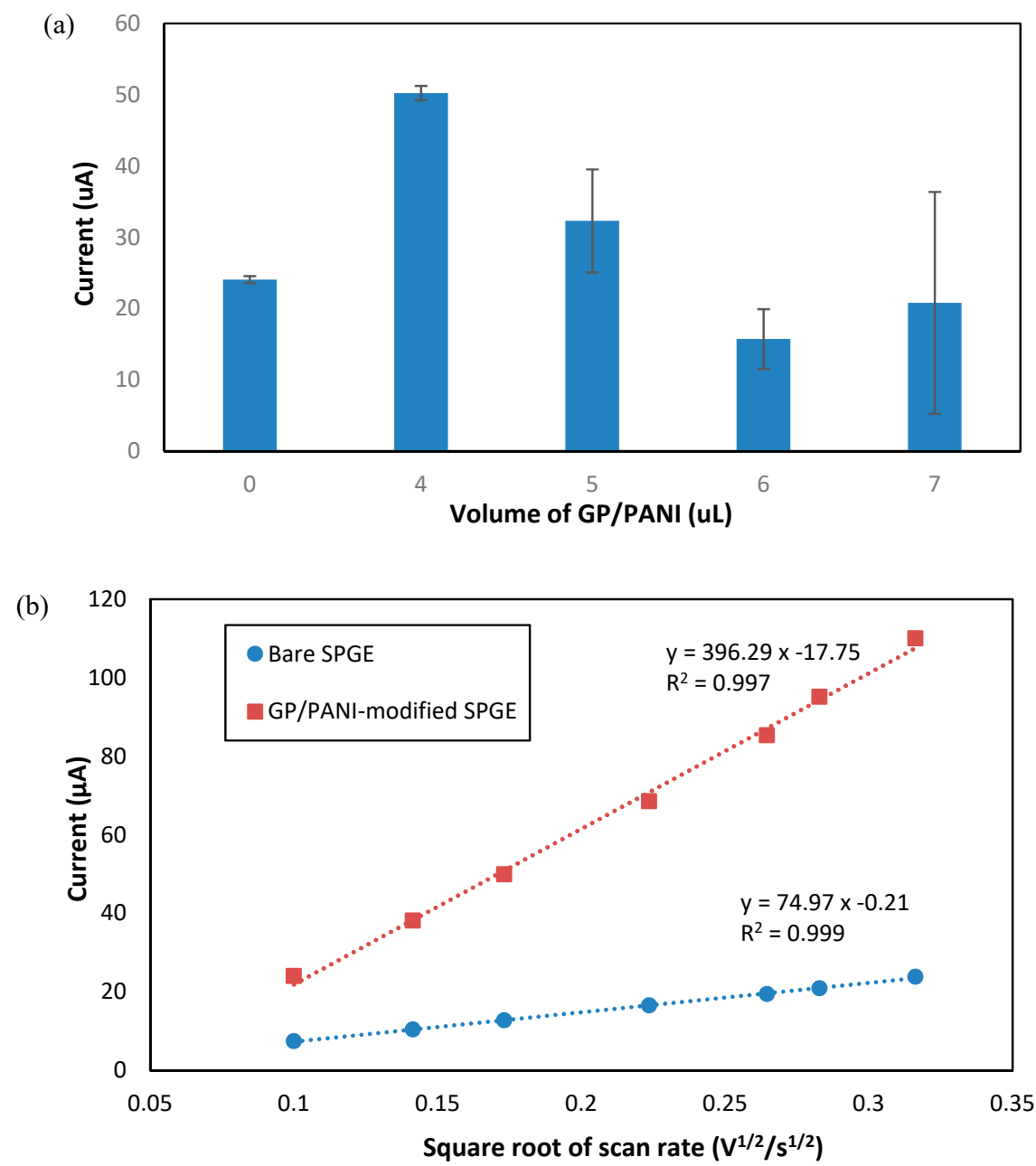

Figure 4. (a) Histogram of different amount of GP/PANI ( $\mu \mathrm{L})$ on SPGE. (b) The relationship of oxidation peak current and square root of scan rates for bare SPGE and GP/PANI-modified SPGE.

\subsection{Sandwich Electrochemical Immunosensor for CFP10 Detection Using GP/PANI-Modified SPGE}

A differential pulse voltammetry (DPV) technique was used in this study to measure the immunoreaction in detection of CFP10. Figure 5 shows the electrochemical responses of bare SGPE, SPGE/GP/PANI, SPGE/GP/PANI/CapAb, SPGE/GP/PANI/CapAb/CFP10/Ab-Fe@Au, SPGE/GP/PANI/CapAb/BSA/Ab-Fe@Au and SPGE/Fe@Au that were characterized using DPV 
in $0.01 \mathrm{M}$ PBS (pH 7.4) containing $2.7 \mathrm{mM} \mathrm{KCl}$. It is clearly observed that the bare SPGE (peak a) produce a small oxidation peak current compared to GP/PANI-modified SPGE (peak b). Besides that, the oxidation peak current of bare SPGE was observed at $0.9 \mathrm{~V}$ but after modification of electrode with GP/PANI, the oxidation peak current was shifted to a lower positive potential, which indicates that the developed immunosensor have improved the electronic transport capacity [13]. The enhanced electrochemical response in the oxidation processes indicated the electroconducting properties of the GP/PANI nanocomposite in facilitating the electron transfer between the electrode surface and chloride ion [13]. After stepwise immobilization the modified electrode with capture antibody (CapAb) (peak c) and Ab-Fe@Au with CFP10 antigen (peak d), the peak currents gradually increase might be due to the signal enhancement of Fe@Au MNPs [32]. Meanwhile, for the SPGE/GP/PANI/CapAb/BSA/Ab-Fe@Au (peak e), the peak current decrease, showing that the Fe@Au MNPs did not attach on the surface of the electrode.

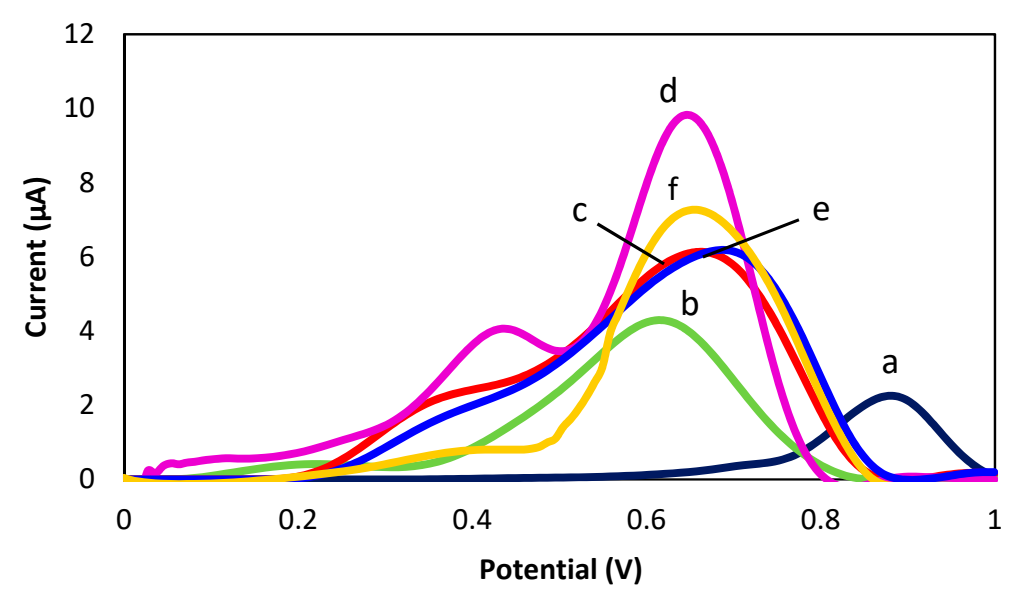

Figure 5. DPV responses of (a) bare SGPE; (b) SPGE/GP/PANI; (c) SPGE/GP/PANI/CapAb; (d) SPGE/GP/PANI/CapAb/CFP10/Ab-Fe@Au; (e) SPGE/GP/PANI/CapAb/BSA/Ab-Fe@Au and (f) SPGE/Fe@Au in 0.01 M PBS solution ( $\mathrm{pH} 7.4)$.

The sensitivity of DPV using the developed sensor towards different concentrations of $M$. tuberculosis CFP10 antigen was studied in the range of 20 to $100 \mathrm{ng} / \mathrm{mL}$. The correlation between the DPV current and the target concentrations as obtained in Figure $6 \mathrm{a}$ indicates that the detection responses of the immunosensor was linear with the value of the complementary target with the linear regression of $R^{2}=0.99$. An increase in peak current was observed as the concentration of CFP10 was increased. The device sensitivity was approximately $3.41 \times 10^{-7} \mathrm{~A} / \mathrm{ng} \cdot \mathrm{mL}^{-1}$ calculated from the curved plotted in the Figure 6a. The detection response of the developed immunosensor can be expressed as the relative change in current $\left(\Delta \mathrm{I} / \mathrm{I}_{0}\right)$, where $\Delta \mathrm{I}$ is the change in peak current after the target detection and $\mathrm{I}_{0}$ is the peak current corresponding to the probe (capture antibody) immobilization response [33]. The relative change of peak current towards different concentrations of CFP10 is plotted in Figure 6b. The significant current change around $5 \%$ was obtained as $100 \mathrm{ng} / \mathrm{mL}$ of CFP10 was employed on the developed immunoassay. As the concentration of CFP10 was decreased to 60,50 and $40 \mathrm{ng} / \mathrm{mL}$, a descending trend of detection response was observed approximately $3.5 \%, 3.2 \%$ and $2.4 \%$, respectively. Meanwhile, merely $0.7 \%$ current change was recorded when $20 \mathrm{ng} / \mathrm{mL}$ of CFP10 was introduced. The limit of detection (LOD) can be defined as $Y_{L O D}=Y_{\text {probe }}+3 \sigma$; where $Y_{\text {probe }}$ is the mean of the probe measurement and $\sigma$ is the standard deviation of the calibration curve [34,35]. The linear regression equation of the plots shown in Figure $6 \mathrm{~b}$ is $\mathrm{Y}_{\mathrm{LOD}}=5.7 \log _{10} \mathrm{x}+44.65$, where $\mathrm{x}$ is the concentration of target CFP10 antigen and $\mathrm{Y}_{\mathrm{LOD}}$ is calculated from the equation. The calculated LOD obtained in this work was approximately $15 \mathrm{ng} / \mathrm{mL}$. This was estimated as the lowest concentration of target CFP10 that can be provided a detectable electronic signal. The developed immunosensor assay can meet the demands of detecting the CFP10 in real sample, as the physiological range of interest of CFP10 is around $100 \mathrm{ng} / \mathrm{mL}$ [36]. Remarkably, this approach 
compared reasonably in term of linearity range and LOD with other previously reported CFP10-based detections as summarized in Table 1.
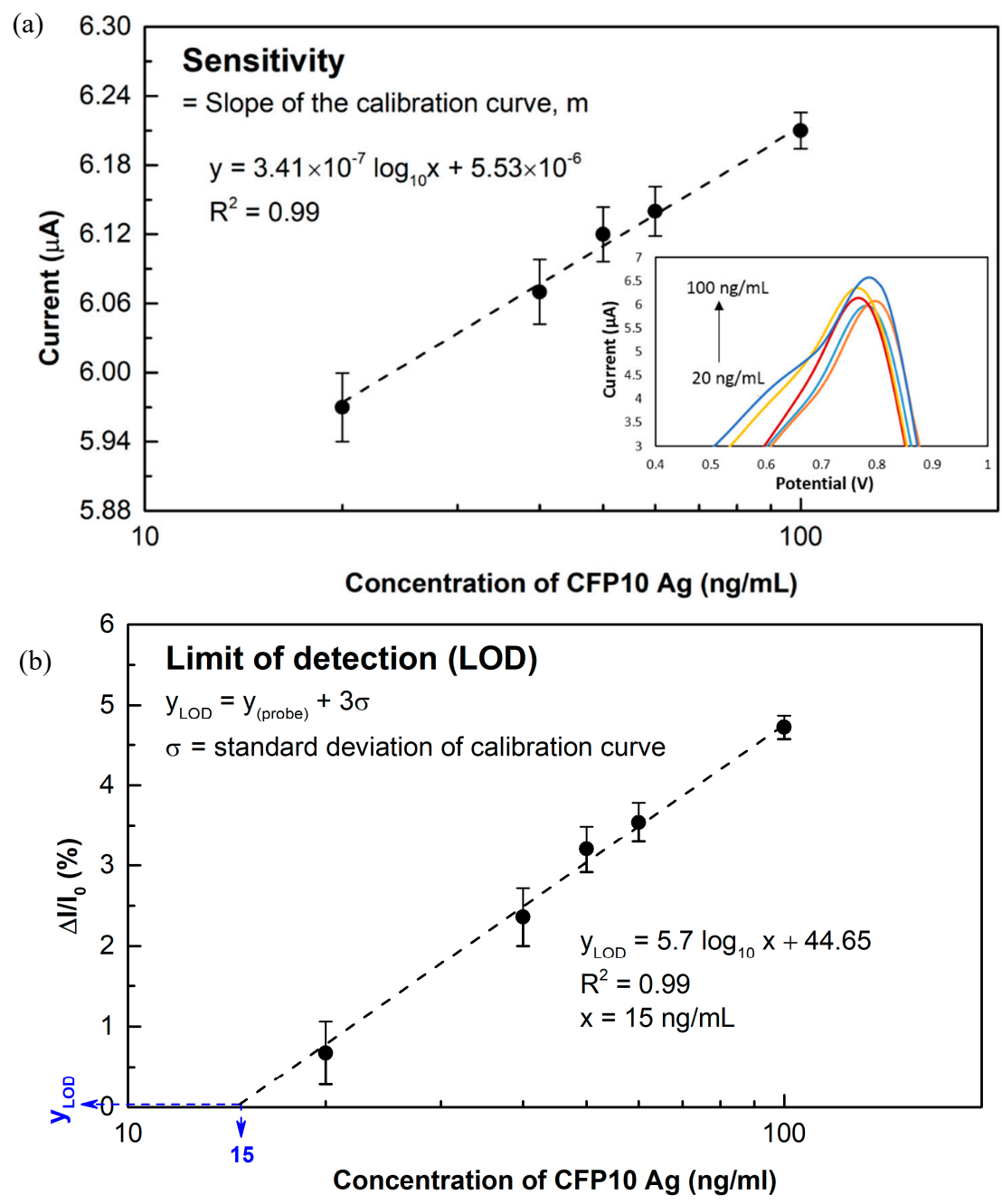

Figure 6. (a) Sensitivity study for the detection of CFP10 at concentrations in the range of $20-100 \mathrm{ng} / \mathrm{mL}$. Inset image shows the DPV responses of the sensor towards the different concentrations of CFP10. (b) Calibration curve of the relative change in current with estimated LOD.

Table 1. Linearity range and LOD of CFP10 antigen using different immunoassay method.

\begin{tabular}{clccc}
\hline No. & \multicolumn{1}{c}{ Detection Method } & Linear Range & LOD & References \\
\hline 1. & Enzyme-linked immunosorbent assay (ELISA) & Not reported & $0.35 \mathrm{IU} / \mathrm{mL}$ & {$[37]$} \\
2. & Plasmonic ELISA & $0-0.1 \mu \mathrm{g} / \mathrm{mL}$ & $0.01 \mu \mathrm{mL}$ & {$[38]$} \\
3. & Magnetophoretic immunoassay & $1 \mathrm{pM}-1 \mathrm{mM}$ & $0.3 \mathrm{pM}$ & {$[39]$} \\
4. & Surface plasmon resonance (SPR) & 0.1 to $1 \mu \mathrm{g} / \mathrm{mL}$ & $100 \mathrm{ng} / \mathrm{mL}$ & {$[40]$} \\
5. & Electrochemical & $20-100 \mathrm{ng} / \mathrm{mL}$ & $15 \mathrm{ng} / \mathrm{mL}$ & This work \\
\hline
\end{tabular}

In order to test the validity of this method in real sample application, the developed immunosensor was then applied for the determination of $M$. tuberculosis CFP10 antigen in sputum samples. Five sputum samples consisted of four sputum samples from positive TB patients and one from a healthy person as the control experiment were collected from Hospital Universiti Sains Malaysia (HUSM). The fresh sputum samples were supplied to the Science laboratory at School of Medical Science (USM) and smear microscope examination was implemented prior to the culture method. The electrochemical analysis was performed simultaneously in the same workspace. We found that this electrochemical immunosensor showed the same trend of signals for all positive TB patients' samples 
(Sample 1-Sample 4) as depicted in Figure 7, which obviously tended to give the highest signal change as compare to the healthy person sample (negative sample as control). From this viewpoint, we have verified that our developed GP/PANI modified SPGE electrode in a sandwich immunoassay format is feasible for early TB diagnosis through detection of the CFP10-specific antigen using sputum samples.

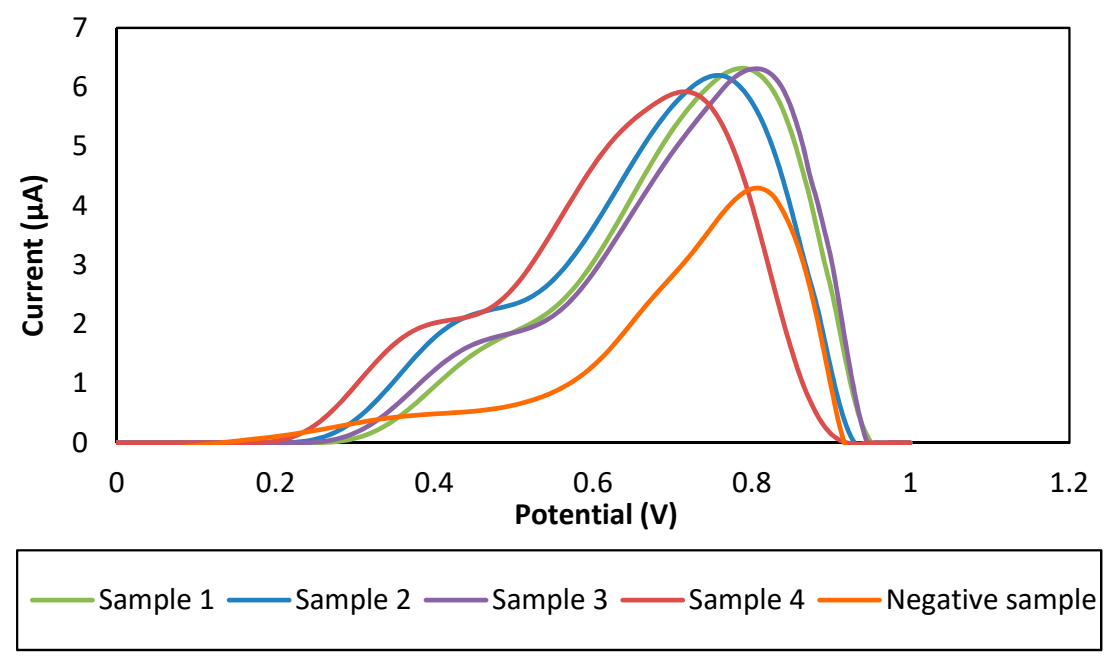

Figure 7. DPV response of sandwich electrochemical immunosensor for CFP10 detection using GP/PANI-modified SPGE in real sample application.

\subsection{Reproducibility of the Developed Immunosensor}

In biosensor performance assessment, reproducibility is a very significant feature in order to identify the reliability in working activity. It can be defined as the capability of a developed immunosensor of producing equivalent feedbacks for a repeated experimental setup [41]. Therefore, it is compulsory to test the reproducibility of the fabricated immunosensor for reliability verification of this method since it is a very significant parameter for immunosensor. For detection of $60 \mathrm{ng} / \mathrm{mL}$ CFP10, a series of five electrodes was setup. Peak currents within the range of 6.094-6.168 $\mu$ A were measured from the developed immunosensors as tabulated in Table 2. Based on the measured peak currents for the five electrodes, the relative standard deviation (RSD) can be calculated from the following equation:

$$
\operatorname{RSD}=(\sigma / \mu) \times 100
$$

where $\sigma$ is standard deviation and $\mu$ is the mean for the measurements. Acceptable RSD of $0.55 \%$ was obtained, which signify the developed immunosensor has an excellent reproducibility for the detection of low concentration CFP10 antigen.

Table 2. Reproducibility of $60 \mathrm{ng} / \mathrm{mL}$ of CFP10 antigen.

\begin{tabular}{ccccc}
\hline Replicate & $\begin{array}{c}\text { Peak Current } \\
(\mu \mathrm{A})\end{array}$ & Mean, $\mu$ & Standard Deviation, $\boldsymbol{\sigma}$ & $\begin{array}{c}\text { Relative Standard Deviation, } \\
\text { RSD (\%) }\end{array}$ \\
\hline 1 & 6.09 & & & \\
2 & 6.16 & & & 0.55 \\
3 & 6.16 & 6.13 & 0.034 & \\
4 & 6.14 & & & \\
5 & 6.10 & & & \\
\hline
\end{tabular}

\section{Conclusions}

In this study, we presented a novel detection strategy that uses GP/PANI-modified SPGE and sandwich immunoassay of TB marker protein CFP10 for early detection of TB infection. This platform employs the CapAb immobilized with GP/PANI as an electrochemical transducer and the Ab was 
conjugated by $\mathrm{Fe}_{3} \mathrm{O}_{4} / \mathrm{Au}$ MNPs allowing for the antigen-specific detection of probes from the assay solution. The morphological and surface analyses of GP/PANI modified on the SPGE surface were studied using FESEM equipped with EDX, which confirmed the existence of N, O and C elements of this nanocomposite on the surface electrode. The Raman spectra showed that the $\mathrm{D}$ band changes significantly with the presence of PANI in GP/PANI modified surface. The presence of the amine groups $\left(\mathrm{NH}_{2}\right)$ in GP/PANI nanocomposite allowed the direct anchoring of the biolayer, which was identified by FTIR spectra at a peak of $1477 \mathrm{~cm}^{-1}$. It was observed that the integration of GP/PANI on SPGE represents an effective strategy in improving about five times sensor performance compared to unmodified SPGE. This method was capable to detect the CFP10 within $3 \mathrm{~h}$ with linearity in the range of $20-100 \mathrm{ng} / \mathrm{mL}\left(\mathrm{R}^{2}=0.99\right)$. The estimated LOD obtained in this work was $15 \mathrm{ng} / \mathrm{mL}$. Moreover, the developed sandwich assay showed exceptional detection response towards CFP10 in sputum specimens for a real sample application and demonstrated high reproducibility (RSD of $0.55 \%$ ) as a disposable-based immunoassay. Our findings signify that TB can be detected in a simple, sensitive and economic way through sputum-based observation, indicating that this assay analysis might be applied in the development of rapid-sensing tools for early TB monitoring.

Author Contributions: U.Z.M.A., N.A.Y. and N.K. contributed to design and fabricated the device. N.A.Y. conceived the project and supervised the work. J.A. and N.H.A.R. supervised the work and helped with the data analysis. The real samples were provided by S.S.M.N. Funding acquisition by P.S.O. Writing-original draft preparation by U.Z.M.A. Writing-review and editing by S.F.A.R. and M.F.M.F.

Funding: This research was supported by NanoMalaysia Berhad, a CLG under the Ministry of Energy, Science, Technology, Environment and Climate Change (MESTECC), Malaysia (Project No. P17014) and by the Putra Grant-Putra Graduate Initiative (GP-IPS), Universiti Putra Malaysia under Grant No. 9528600.

Acknowledgments: The authors would like to thank NanoMalaysia Berhad, a CLG under the Ministry of Energy, Science, Technology, Environment and Climate Change (MESTECC), Malaysia and Universiti Putra Malaysia for their financial support throughout this project.

Conflicts of Interest: The authors declare no conflict of interest.

\section{References}

1. Sypabekova, M.; Bekmurzayeva, A.; Wang, R.; Li, Y.; Nogues, C.; Kanayeva, D. Selection, characterization, and application of DNA aptamers for detection of Mycobacterium tuberculosis secreted protein MPT64. Tuberculosis 2017, 104, 70-78. [CrossRef] [PubMed]

2. Torati, S.R.; Reddy, V.; Yoon, S.S.; Kim, C. Electrochemical biosensor for Mycobacterium tuberculosis DNA detection based on gold nanotubes array electrode platform. Biosens. Bioelectron. 2016, 78, 483-488. [CrossRef] [PubMed]

3. Nurmalasari, R.; Gaffar, S.; Hartati, Y.W. Label-free electrochemical DNA biosensor for the detection of Mycobacterium tuberculosis using gold electrode modified by self-assembled monolayer of thiol. Procedia Chem. 2015, 17, 111-117. [CrossRef]

4. World Health Organization. Global Tuberculosis Report 2016. Available online: http://apps.who.int/ medicinedocs / documents/s23098en/s23098en.pdf (accessed on 30 October 2017).

5. Kim, J.; Lee, J.; Lee, K.I.; Park, T.J.; Kim, H.J.; Lee, J. Rapid monitoring of CFP-10 during culture of Mycobacterium tuberculosis by using a magnetophoretic immunoassay. Sens. Actuators B Chem. 2013, 177, 327-333. [CrossRef]

6. Sun, J.R.; Lee, S.Y.; Perng, C.L.; Lu, J.J. Detecting Mycobacterium tuberculosis in bactec MGIT 960 cultures by inhouse IS6110-based PCR assay in routine clinical practice. J. Formos. Med. Assoc. 2009, 108, $119-125$. [CrossRef]

7. Díaz-González, M.; González-García, M.B.; Costa-García, A. Immunosensor for Mycobacterium tuberculosis on screen-printed carbon electrodes. Biosens. Bioelectron. 2005, 20, 2035-2043. [CrossRef] [PubMed]

8. Renedo, O.D.; Alonso-Lomillo, M.A.; Martínez, M.A. Recent developments in the field of screen-printed electrodes and their related applications. Talanta 2007, 73, 202-219. [CrossRef] [PubMed]

9. Metters, J.P.; Kadara, R.O.; Banks, C.E. New directions in screen printed electroanalytical sensors: An overview of recent developments. Analyst 2011, 136, 1067-1076. [CrossRef] [PubMed] 
10. Cinti, S.; Minotti, C.; Moscone, D.; Palleschi, G.; Arduini, F. Fully integrated ready-to-use paper-based electrochemical biosensor to detect nerve agents. Biosens. Bioelectron. 2017, 93, 46-51. [CrossRef] [PubMed]

11. Fan, Y.; Liu, J.-H.; Yang, C.-P.; Yu, M.; Liu, P. Graphene-polyaniline composite film modified electrode for voltammetric determination of 4-aminophenol. Sens. Actuators B Chem. 2011, 157, 669-674. [CrossRef]

12. Kong, F.; Gu, S.; Li, W.; Chen, T.; Xu, Q.; Wang, W. A paper disk equipped with graphene/polyaniline/Au nanoparticles/glucose oxidase biocomposite modified screen-printed electrode: Toward whole blood glucose determination. Biosens. Bioelectron. 2014, 56, 77-82. [CrossRef] [PubMed]

13. Chan, K.F.; Lim, H.N.; Shams, N.; Jayabal, S.; Pandikumar, A.; Huang, N.M. Fabrication of graphene/gold-modified screen-printed electrode for detection of carcinoembryonic antigen. Mater. Sci. Eng. C 2016, 58, 666-674. [CrossRef] [PubMed]

14. Radhapyari, K.; Kotoky, P.; Das, M.R.; Khan, R. Graphene-polyaniline nanocomposite based biosensor for detection of antimalarial drug artesunate in pharmaceutical formulation and biological fluids. Talanta 2013, 111, 47-53. [CrossRef] [PubMed]

15. Liu, C.; Jang, D.; Xiang, G.; Liu, F.; Liu, L.; Pu, X. An electrochemical DNA biosensor for the detection of Mycobacterium tuberculosis, based on signal amplification of graphene and a gold nanoparticles-polyaniline nanocomposite. Analyst 2014, 139, 5460-5465. [CrossRef] [PubMed]

16. Kaul, K.L. Molecular detection of Mycobacterium tuberculosis: Impact on patient care. Clin. Chem. 2001, 47, 1553-1558. [PubMed]

17. Kraus, G.; Clearly, T.; Miller, N.; Seivright, R.; Young, A.K.; Spruill, G.; Hnatyszyn, H.J. Rapid and specific detection of the Mycobacterium tuberculosis complex using fluorogenic probes and real-time PCR. Mol. Cell. Probes 2001, 15, 375-383. [CrossRef] [PubMed]

18. Mohamad, S.F.; Mat Zaid, H.M.; Abdullah, J.; Zawawi, M.R.; Lim, N.H.; Sulaiman, Y.; Abdul Rahman, N. Synthesis and characterization of polyaniline/graphene composite nanofiber and its application as an electrochemical DNA biosensor for the detection of Mycobacterium tuberculosis. Sensors 2017, 17, 2789. [CrossRef] [PubMed]

19. Pereira Arias-Bouda, L.M.; Nguyen, L.N.; Ho, L.Y.M.; Kuijper, S.; Jansen, H.M.; Kolk, A.H.J. Development of antigen detection assay for diagnosis of tuberculosis using sputum samples. J. Clin. Microbiol. 2000, 38, 2278-2283. [PubMed]

20. Yáñez, M.A.; Coppola, M.P.; Russo, D.A.; Delaha, E.; Chaparas, S.D.; Yeager, H., Jr. Determination of mycobacterial antigens in sputum by enzyme immunoassay. J. Clin. Microbiol. 1986, 23, 822-825. [PubMed]

21. Sada, E.; Ruiz-Palacios, G.M.; López-Vidal, Y.; Ponce de León, S. Detection of mycobacterial antigens in cerebrospinal fluid of patients with tuberculosis meningitis by enzyme-linked immunosorbent assay. Lancet 1983, 322, 651-652. [CrossRef]

22. Choudhry, V.; Saxena, R.K. Detection of Mycobacterium tuberculosis antigens in urinary proteins of tuberculosis patients. Eur. J. Clin. Microbiol. Infect. Dis. 2002, 21, 1-5. [CrossRef] [PubMed]

23. Reither, K.; Saathoff, E.; Jung, J.; Minja, L.T.; Kroidl, I.; Saad, E.; Huggett, J.F.; Ntinginya, E.N.; Maganga, L.; Maboko, L.; et al. Low sensitivity of a urine LAM-ELISA in the diagnosis of pulmonary tuberculosis. BMC Infect. Dis. 2009, 9, 141. [CrossRef] [PubMed]

24. Koo, H.C.; Park, Y.H.; Ahn, J.; Waters, W.R.; Palmer, M.V.; Hamilton, M.J.; Barrington, G.; Mosaad, A.A.; Park, K.T.; Jung, W.K.; et al. Use of rMPB70 protein and ESAT-6 peptide as antigens for comparison of the enzyme linked immunosorbent, immunochromatographic, and latex bead agglutination assays for serodiagnosis of bovine tuberculosis. J. Clin. Microbiol. 2005, 43, 498-506. [CrossRef] [PubMed]

25. Cui, Y.-R.; Hong, C.; Zhou, Y.-L.; Li, Y.; Gao, X.-M.; Zhang, X.-X. Synthesis of orientedly bioconjugated core/shell $\mathrm{Fe}_{3} \mathrm{O}_{4} @ \mathrm{Au}$ magnetic nanoparticles for cell separation. Talanta 2011, 85, 1246-1252. [CrossRef] [PubMed]

26. Zhao, X.; Cai, Y.; Wang, T.; Shi, Y.; Jiang, G. Preparation of alkanethiolate-functionalized core/shell $\mathrm{Fe}_{3} \mathrm{O}_{4} @ \mathrm{Au}$ nanoparticles and its interaction with several typical target molecules. Anal. Chem. 2008, 80, 9091-9096. [CrossRef] [PubMed]

27. Wei, Q.; Xiang, Z.; He, J.; Wang, G.; Li, H.; Qian, Z.; Yang, M. Dumbbell-like Au-Fe $\mathrm{O}_{4}$ nanoparticles as label for the preparation of electrochemical immunosensors. Biosens. Bioelectron. 2010, 26, 627-631. [CrossRef] [PubMed] 
28. Rashid, J.I.A.; Yusof, N.A.; Abdullah, J.; Hashim, U.; Hajian, R. The utilization of SiNWs/AuNPs-modified indium tin oxide (ITO) in fabrication of electrochemical DNA sensor. Mater. Sci. Eng. C 2014, 45, 270-276. [CrossRef] [PubMed]

29. Mat Zaid, M.H.; Abdullah, J.; Yusof, N.A.; Sulaiman, Y.; Wasoh, H.; Md Noh, M.F.; Issa, R. PNA biosensor based on reduced graphene oxide/water soluble quantum dots for the detection of Mycobacterium tuberculosis. Sens. Actuators B Chem. 2017, 241, 1024-1034. [CrossRef]

30. Yan, C.; Kanaththage, Y.W.; Short, R.; Gibson, C.T.; Zou, L. Graphene/Polyaniline nanocomposite as electrode material for membrane capacitive deionization. Desalination 2014, 344, 274-279. [CrossRef]

31. Wan, H.; Sun, Q.; Li, H.; Sun, F.; Hu, N.; Wang, P. Screen-printed gold electrode with gold nanoparticles modification for simultaneous electrochemical determination of lead and copper. Sens. Actuators B Chem. 2015, 209, 336-342. [CrossRef]

32. Duangkaew, P.; Tapaneeyakorn, S.; Apiwat, C.; Dharakul, T. Ultrasensitive electrochemical immunosensor based on dual signal amplification process for p16 INK4a cervical cancer detection in clinical samples. Biosens. Bioelectron. 2015, 74, 673-679. [CrossRef] [PubMed]

33. Bizid, S.; Blili, S.; Mlika, R.; Haj Said, A.; Korri-Youssoufi, H. Direct E-DNA sensor of Mycobacterium tuberculosis mutant strain based on new nanocomposite transducer (Fc-ac-OMPA/MWCNTs). Talanta 2018, 184, 475-483. [CrossRef] [PubMed]

34. Nuzaihan, M.N.M.; Hashim, U.; Md Arshad, M.K.; Kasjoo, S.R.; Rahman, S.F.A.; Ruslinda, A.R.; Fathil, M.F.M.; Adzhri, R.; Shahimin, M.M. Electrical detection of dengue virus (DENV) DNA oligomer using silicon nanowire biosensor with novel molecular gate control. Biosens. Bioelectron. 2016, 83, 106-114. [CrossRef] [PubMed]

35. Rahman, S.F.A.; Yusof, N.A.; Hashim, U.; Hushiarian, R.; Nuzaihan, M.N.M.; Hamidon, M.N.; Zawawi, R.M.; Fathil, M.F.M. Enhanced sensing of dengue virus DNA detection using $\mathrm{O}_{2}$ plasma treated-silicon nanowire based electrical biosensor. Anal. Chim. Acta 2016, 942, 74-85. [CrossRef] [PubMed]

36. Dai, Z.; Liu, Z.; Xiu, B.; Yang, X.; Zhao, P.; Zhang, X.; Duan, C.; Que, H.; Zhang, H.; Feng, X. A multiple-antigen detection assay for tuberculosis diagnosis based on broadly reactive polyclonal antibodies. Iran. J. Basic Med. Sci. 2017, 20, 360-367. [PubMed]

37. Metcalfe, J.Z.; Cattamanchi, A.; McCulloch, C.E.; Lew, J.D.; Ha, N.P.; Graviss, E.A. Test variability of the QuantiFERON-TB gold in-tube assay in clinical practice. Am. J. Respir. Crit. Care Med. 2013, 187, $206-211$. [CrossRef] [PubMed]

38. Mohd Bakhori, N.; Yusof, A.N.; Abdullah, J.; Wasoh, H.; Md Noor, S.S.; Ahmad Raston, H.N.; Mohammad, F. Immuno nanosensor for the ultrasensitive naked eye detection of tuberculosis. Sensors 2018, 18, 1932. [CrossRef] [PubMed]

39. Kim, J.; Lee, K.S.; Kim, E.B.; Paik, S.; Chang, C.L.; Park, T.J.; Kim, H.-J.; Lee, J. Early detection of the growth of Mycobacterium tuberculosis using magnetophoretic immunoassay in liquid culture. Biosens. Bioelectron. 2017, 96, 68-76. [CrossRef] [PubMed]

40. Hong, S.C.; Chen, H.; Lee, J.; Park, H.-K.; Kim, Y.S.; Shin, H.-C.; Kim, C.-M.; Park, T.J.; Lee, S.J.; Koh, K.; et al. Ultrasensitive immunosensing of tuberculosis CFP-10 based on SPR spectroscopy. Sens. Actuators B Chem. 2011, 156, 271-275. [CrossRef]

41. Bhalla, N.; Jolly, P.; Formisano, N.; Estrela, P. Introduction to biosensors. Essays Biochem. 2016, 60, 1-8. [CrossRef] [PubMed]

(C) 2018 by the authors. Licensee MDPI, Basel, Switzerland. This article is an open access article distributed under the terms and conditions of the Creative Commons Attribution (CC BY) license (http://creativecommons.org/licenses/by/4.0/). 